\title{
Patient Self-Education and the Internet: An Evaluation of the Internet Contents Regarding Axial Lumbar Intervertebral Fusion (AxiaLIF)
}

\author{
Mhamad Faour ${ }^{1}$, Joshua T Anderson ${ }^{2}$, Uri M Ahn ${ }^{3}$ and Nicholas U Ahn ${ }^{1}$ \\ ${ }^{1}$ Department of Orthopaedics, University Hospitals Case Medical Center, USA \\ ${ }^{2}$ Department of Orthopaedics, Case Western Reserve University School of Medicine, USA \\ ${ }^{3}$ New Hampshire Neuro Spine Institute, USA
}

Submission: September 21, 2017; Published: October 02, 2017

*Corresponding author: Mhamad Faour, Department of Orthopaedics, University Hospitals Case Medical Center, 11100 Euclid Avenue, Cleveland, OH 44106, USA, Tel: 281-746-5153; Fax: 216-844-1735; Email: mhamad.faour@hotmail.com

Abstract

Introduction: The internet has become the main source of information for medical conditions and treatment options. The AxiaLIF system is a novel minimally invasive fusion technique for the treatment of single-level fusion. The evidence to support the efficacy and the safety of the procedure is lacking. Our study aimed to evaluate how accurate and reliable is the information on the internet regarding the AxiaLIF.

Methods: Google, Yahoo, and Bing, were used to find the top 105 sites (35 per engine) providing information on AxiaLIF. These sites were then divided into groups based on authorship. Each site was comprehensively analyzed for information about the procedure. Data were collected and evaluated for each authorship subgroup as well as for the entire group of websites.

Results: Of the sites examined, $41 \%$ were authored by news and public reports group, $33 \%$ by private medical groups, $19 \%$ by academic medical groups, and $7 \%$ by medical industry. All of the websites offered at least one indication for the AxiaLIF. Only $7 \%$ of these sites contained contraindications for the procedure. While only $7 \%$ of the sites addressed the lack of strong evidence in the literature favoring AxiaLIF over traditional approaches, about one third of the websites claimed that AxiaLIF is an alternative to traditional surgical procedures. Benefits were extensively reported in all the websites, the highest reporting rate was in the industry group with an average of 2.4 per website. In contrast, one or more complications were reported in $74 \%$ of all websites.

Conclusion: This study demonstrated that the internet is ineffective in comprehensively reporting critically important information for patients regarding the AxiaLIF procedure. Physicians should make efforts to counsel patients regarding the limitations of the information present on the internet.

Keywords: Minimally invasive surgery; Presacral access; L5-S1 fusion; AxiaLIF; Axial Lumbar fusion; Internet; Patient education

\section{Introduction}

In recent years advances in minimally invasive surgery has allowed surgeons to treat a wider range of spinal disorders. Nonetheless, standard minimally invasive lumbar fusion techniques still use the same anatomic approach and theoretically place the same structures at risk for iatrogenic injury. The AxiaLIF System, a novel minimally invasive fusion technique, received marketing clearance from the US FDA in December 2004 for treatment of single-level fusion [1], and the AxiaLIF 2-Level System for 2-level fusion was cleared in April 2008 [2].

It was proposed that the AxiaLIF technique has several advantages including small incision, muscle-sparing approach, preservation of the annulus, and access through the relatively safe corridor. The placement of an axial implant with annular and muscular preservation has the theoretic potential to achieve fusion rates comparable to the ALIF and direct lateral approaches without the concerns of vascular injury, retrograde ejaculation, or nerve root injury [3-12]. The Internet has become the most popular source of health care information. The objective of this study was to evaluate the quality of the internet contents made to public about the controversial axial lumbar intervertebral body fusion (AxiaLIF). We aimed to determine how accurate this information to what exists in the primary literature about AxiaLIF, and how patient decision-making could foresee ably be affected by such information. 


\section{Materials and Methods}

Our study design attempted to model the patient internet search experience as closely as possible. Three commonly used search engines were identified: Google, Yahoo!, and Microsoft Bing. Each of these engines was used to search for the general term "AxiaLIF". The top 35 sites identified using each search engine were analyzed to compile a total data set of 105 sites consistent with the numbers evaluated in prior studies [1317]. Duplicate sites within and between search engines were discarded, as were sites that were identical with the exception of URL. Sites directly linking to publications in academic journals were excluded. Our search was carried out using a naïve internet browser to limit bias from prior medically related browsing history, and location services for each search engine were disabled to reduce geographic impact on search results.

Each site was first evaluated on the basis of sponsorship. Sites were classified into one of four categories: Academic, Private, Industry, or Others. Sites sponsored by accredited universities or university affiliated healthcare institutions were defined to be Academic. Sites sponsored by a privately operating Table 1: Overview of the AxiaLIF system. physician or group of physicians or sites sponsored by a private corporation and edited by a privately operating physician or group of physicians were classified as Private. Sites sponsored by biomedical device corporations were considered to be Industry. Sites falling outside of these three categories were categorized as others, these sites included, blogs, news articles or reports about AxiaLIF, and websites that couldn't be categorized otherwise.

The appropriate indications, contraindications, claimed benefits, risks or complications, and the alternative nonsurgical treatments were all collected and recorded (Table 1). The statement, that strong evidence for better outcomes of AxiaLIF over other traditional procedures has not yet been demonstrated in the literature, was investigated and reported from each site. The statement that the AxiaLIF is an alternative to the traditional approaches was evaluated and reported from each website. We didn't account for the date of the websites, as patients might not be influenced by date of the sites when they are interpreting data. Whether sites offered step-by-step description or illustration of the procedure or the implants was also recorded.

\begin{tabular}{|c|c|c|c|c|}
\hline & & AxiaLIF System & & \\
\hline Indications & Contraindications & Benefits & Risks/Complications & $\begin{array}{c}\text { Alternative non-surgical } \\
\text { treatments }\end{array}$ \\
\hline $\begin{array}{l}\text { 1. Degenerative disc } \\
\text { disease. } \\
\text { 2. Multiple recurrent disc } \\
\text { herniation } \\
\text { 3. Degenerative lumbar } \\
\text { scoliosis } \\
\text { 4. Spondylolisthesis } \\
\text { (Grade I or II) } \\
\text { 5. Pseudoarthrosis } \\
\text { 6. Symptomatic instability }\end{array}$ & $\begin{array}{l}\text { 1. Coagulopathy } \\
\text { 2. Bowel Disease } \\
\text { 3. Pregnancy } \\
\text { 4. Sacral agenesis } \\
\text { 5. Previous surgery } \\
\text { (compromised access or } \\
\text { bowel adhesions) } \\
\text { 6. Treatment of Tumor or } \\
\text { Trauma } \\
\text { 7. Spondylolisthesis } \\
\text { (Grade III and IV) }\end{array}$ & $\begin{array}{c}\text { Reduction in : } \\
\text { 1. Pain } \\
\text { 2. Musculo-ligamentous } \\
\text { damage } \\
\text { 3. Blood loss } \\
\text { 4. Hospital Stay } \\
\text { 5. Post-operative narcotic } \\
\text { use }\end{array}$ & $\begin{array}{l}\text { 1. Bowel Injury } \\
\text { 2. Hypotension } \\
\text { 3. Para-sacral Hematoma } \\
\text { 4. Sacral fracture } \\
\text { 5. Vascular injury } \\
\text { 6. Infection (Systemic, } \\
\text { Surgical site) } \\
\text { 7. Rod migration } \\
\text { 8. Graft subsidence } \\
\text { 9. Nerve injury } \\
\text { 10. Ureter injury }\end{array}$ & $\begin{array}{l}\text { 1. NSAIDs } \\
\text { 2. Muscle relaxant } \\
\text { 3. Chiropractor } \\
\text { manipulation } \\
\text { 4. Epidural injections } \\
\text { 5. TENS units } \\
\text { 6. Ultrasound } \\
\text { 7. Massage } \\
\text { 8. Heat/Ice therapy } \\
\text { 9.Acupuncture } \\
\text { 10. Exercise } \\
\text { 11. Weight reduction } \\
\text { 12. Ergonomics }\end{array}$ \\
\hline
\end{tabular}

NSAIDs: Non-Steroidal Anti-Inflammatory Drugs; TENS: Transcutaneous Electrical Nerve Stimulators

Lastly, recent updates to each website were not taken into account, so the information identified could theoretically have been outdated. However, the point was to simulate what the internet search would be like for a patient. In addition, when reporting variables, rates between groups were not compared or checked for any statistically significant differences. Rather, we wished to look for reporting trends within the available information on the internet. Each variable was analyzed as binary data. For each variable, the total number of sites and the number of sites within each category of authorship that provided sufficient information for that particular variable were reported. Also, the total percent of all 105 websites as well as the percent of websites within each category of authorship that reported each variable were calculated.

No funding was received for this study, nor were there any conflict of interests.

\section{Results}

Upon searching the term "AxiaLIF", about 85.000 sites emerged between Google, which had about 20.800 sites, Yahoo, which had about 29.400 sites, and Bing, which had about 35.700 sites. Analysis of the top 105 sites collected for the sponsorship 


\section{Orthopedics and Rheumatology Open Access Journal}

showed that of the 105 sites evaluated $41 \%$ were others, 33\% were private, $19 \%$ were Academic, and $7 \%$ were Industrial. of all the websites, at least one indication was reported per website for the AxiaLIF procedure. Contraindications of the procedure were reported in only $7 \%$ of the total websites. More details are presented in Table 2. The role of AxiaLIF as an alternative to traditional approaches was mentioned in 36 websites (34\%). The statement of lack of strong evidence favoring outcomes of AxiaLIF over other traditional procedures was mentioned only in 7 websites (7\%). (Table 3).

Table 2: sites by Authorship, Indications, mean of indications per website, and contraindications of the AxiaLIF procedure.

\begin{tabular}{|c|c|c|c|c|}
\hline Authorship & Number of sites (\%) & Indications & Mean of indications & Contraindications (\%) \\
\hline Academic & $20(19 \%)$ & 20 & 1 & $0(0 \%)$ \\
\hline Private & $35(33 \%)$ & 43 & 1.2 & $1(3 \%)$ \\
\hline Industry & $7(7 \%)$ & 7 & 1.0 & $6(86 \%)$ \\
\hline Others & $43(41 \%)$ & 40 & 1.0 & $0(0 \%)$ \\
\hline Total & $105(100 \%)$ & 110 & $7 \%)$ & $7(7 \%)$ \\
\hline
\end{tabular}

Table 3: Mention of lack of strong evidence for better outcomes of AxiaLIF, and mention of AxiaLIF as an alternative procedure for traditional approaches.

\begin{tabular}{|c|c|c|}
\hline Authorship & No better outcomes (\%) & Alternative to traditional approaches (\%) \\
\hline Academic & $2(10 \%)$ & $5(25 \%)$ \\
\hline Private & $1(3 \%)$ & $2(31 \%)$ \\
\hline Industry & $0(0 \%)$ & $18(42 \%)$ \\
\hline Others & $4(9 \%)$ & $36(34 \%)$ \\
\hline Total & $7(7 \%)$ & \\
\hline
\end{tabular}

Table 4: Benefits claimed form AxiaLIF over traditional procedures.

\begin{tabular}{|c|c|c|c|c|c|}
\hline Benefits & Academic (n=20) (\%) & Private (n=35) (\%) & Industry (n=7) (\%) & Others (n=43) (\%) & Total (n=105) (\%) \\
\hline Less pain & $13(65 \%)$ & $19(54 \%)$ & $4(57 \%)$ & $23(53 \%)$ & $59(56 \%)$ \\
\hline Less muscle damage & $8(40 \%)$ & $9(26 \%)$ & $4(57 \%)$ & $14(33 \%)$ & $35(33 \%)$ \\
\hline Less blood loss & $3(15 \%)$ & $6(17 \%)$ & $3(43 \%)$ & $5(16 \%)$ & $19(18 \%)$ \\
\hline Less hospital stay & $13(65 \%)$ & $24(69 \%)$ & $5(71 \%)$ & $26(60 \%)$ & $68(65 \%)$ \\
\hline $\begin{array}{c}\text { less narcotic use after } \\
\text { surgery }\end{array}$ & $1(5 \%)$ & $0(0 \%)$ & $1(14 \%)$ & $1(2 \%)$ & $3(3 \%)$ \\
\hline Total & 38 & 58 & 17 & 21 & 1.7 \\
\hline Mean Benefit/website & 1.9 & 1.7 & 2.4 & 1.8 & 1.8 \\
\hline
\end{tabular}

Table 5: Risks and complications of AxiaLIF.

\begin{tabular}{|c|c|c|c|c|c|}
\hline Risks/Complications & Academic (n=20) (\%) & Private (n=35) (\%) & Industry (n=7) (\%) & Others (n=43) (\%) & Total (n=105) (\%) \\
\hline Bowel Injury & $3(15 \%)$ & $3(9 \%)$ & $1(14 \%)$ & $6(14 \%)$ & $13(12 \%)$ \\
\hline Hypotension & $0(0 \%)$ & $2(6 \%)$ & $1(14 \%)$ & $2(5 \%)$ & $5(5 \%)$ \\
\hline Pre-sacral hematoma & $2(10 \%)$ & $0(0 \%)$ & $0(0 \%)$ & $2(5 \%)$ & $4(4 \%)$ \\
\hline Sacral Fracture & $0(0 \%)$ & $0(0 \%)$ & $0(0 \%)$ & $2(5 \%)$ & $2(2 \%)$ \\
\hline Vascular injury & $2(10 \%)$ & $2(6 \%)$ & $1(14 \%)$ & $4(9 \%)$ & $9(9 \%)$ \\
\hline Nerve injury & $2(10 \%)$ & $2(6 \%)$ & $1(14 \%)$ & $2(5 \%)$ & $7(7 \%)$ \\
\hline Systemic infection & $2(10 \%)$ & $3(9 \%)$ & $1(14 \%)$ & $6(14 \%)$ & $12(11 \%)$ \\
\hline Wound infection & $1(5 \%)$ & $3(9 \%)$ & $1(14 \%)$ & $6(14 \%)$ & $11(10 \%)$ \\
\hline Cephalic Rod & $1(5 \%)$ & $1(3 \%)$ & $0(0 \%)$ & $3(7 \%)$ & $5(5 \%)$ \\
\hline migration & $2(10 \%)$ & $2(6 \%)$ & $0(0 \%)$ & $2(5 \%)$ & $6(6 \%)$ \\
\hline Graft subsidence & $0(0 \%)$ & $2(6 \%)$ & $0(0 \%)$ & $2(5 \%)$ & $4(4 \%)$ \\
\hline Ureter injury & $15(75 \%)$ & $20(57 \%)$ & $6(86 \%)$ & $37(86 \%)$ & $78(74 \%)$ \\
\hline Total & & & & 2 \\
\hline
\end{tabular}

Benefits of the AxiaLIF discussed among all websites include pain reduction in 59 websites (56\%), less musculoligamentous damage in 35 websites (33\%), less blood loss in 19 websites $(18 \%)$, less hospitals stay in 68 websites $(65 \%)$ and less narcotic use after surgery in 3 websites (3\%). Benefits were discussed in details in Table 4. Risks and potential complications of the AxiaLIF reported by all websites include: bowel injury in 13 websites $(12 \%)$, hypotension in 5 websites $(5 \%)$, Presacral 
hematoma in 4 websites (4\%), sacral fracture in 2 websites (2\%), vascular injury in 9 websites $(9 \%)$, nerve injury in 7 websites (7\%), systemic infection in 12 websites $(11 \%)$, wound infection in 11 websites (10\%), cephalic rod migration in 5 websites (5\%), graft subsidence in 6 websites (6\%), and ureter injury in 4 websites (4\%). Further analysis by authorship group is included in Table 5. Alternative treatments for AxiaLIF were mentioned in 2 academic websites, 3 private websites, 3 other 1 websites, none of the industry websites. Thirty seven percent of all the websites offered illustrative images or videos of the surgery and the implants, and $62 \%$ of all the websites provided step by step description of the procedure (Table 6).

Table 6: Mention of description and illustrations of the procedure and alternative non-surgical treatments in the websites.

\begin{tabular}{|c|c|c|c|}
\hline Authorship & Illustrations of the procedure (\%) & Description of the procedure (\%) & Alternative non-surgical treatments (\%) \\
\hline Academic & $8(40 \%)$ & $12(60 \%)$ & $2(10 \%)$ \\
\hline Private & $20(57 \%)$ & $33(94 \%)$ & $3(9 \%)$ \\
\hline Industry & $2(29 \%)$ & $4(57 \%)$ & $3(0 \%)$ \\
\hline Others & $39(37 \%)$ & $16(37 \%)$ & $8(8 \%)$ \\
\hline Total & & $65(62 \%)$ & \\
\hline
\end{tabular}

\section{Discussion}

The AxiaLIF system (TranS1, Inc., Wilmington, NC) was developed as a minimally invasive method to perform an L5-S1 interbody fusion to treat low back pain of discogenic origin at the level of the L5-S1 disc space. The AxiaLIF approach is presumed to be a percutaneous alternative to the anterior, posterior, or transforaminal lumbar interbody fusion techniques. This makes it the first truly minimally invasive, percutaneously placed lumbar interbody device using the presacral fat bed. The device is indicated for degenerative disc disease (DDD) with or without radicular symptoms, pseudoarthrosis from a prior unsuccessful fusion, and/or spondylolisthesis (Grade 1 or 2). Although the presacral corridor is considered an anatomic safe zone, access through this region can be safely exploited only if the surgeon is intimately familiar with the relevant pelvic anatomy because the entire procedure is visualized under fluoroscopy with no direct observation of the disc space $[18,19]$.

The peer-reviewed published literature reporting outcomes for axial lumbar interbody fusion remains limited to retrospective case series, review articles, and technical reports [20-29]. To date, there are no randomized controlled trials that support the efficacy and safety of axial lumbar interbody fusion as a minimally invasive or percutaneous surgical procedure for the treatment of L5-S1 conditions. Evidence supporting improved clinical outcomes such as pain relief, improvement in function, and successful fusion rates are limited [20-24]. Randomized controlled studies with larger numbers of participants reporting improved clinical outcomes and a decrease in overall complication rates are needed to determine the long term efficacy and safety of axial lumbar interbody fusion for any indication.

With all the controversy of the AxiaLIF approach, it is of the utmost importance that patients have a comprehensive and accurate understanding of the AxiaLIF system before undergoing the procedure. Increasing number of patients is using the internet as a source of information for their health care problems and medical decision-making. Therefore, it is imperative that publicly available information on the AxiaLIF system over the internet is correct, thorough, and reflects the best interest of the patients suffering from lower back pain. Our purpose was to evaluate the quality of this information.

In reviewing the top 105 websites from 3 independent search engines, the result of this study concluded that much of the information on AxiaLIF available on the internet are insufficient and inaccurate for patients to make medical decisions about the benefits of axial lumbar interbody fusion (AxiaLIF). Our findings were consistent with other studies reporting that the internet doesn't contain all the accurate and important information on orthopedic procedures and conditions [13-17]. Our analysis showed that the majority of websites offering information about AxiaLIF were sponsored by news articles and public reports which accounts for $41 \%$ of the websites and only $19 \%$ of the websites were accounted for academic universities or university affiliated hospitals. This is concerning because patients supposed to look for trusted and thorough information about diseases and treatment options from the academic websites.

All the websites reported at least one indication for the procedure. Private Sites sponsored by a privately operating physician or group of physicians or sites sponsored by a private corporation and edited by a privately operating physician or group of physicians had the highest average of reporting indications for the procedure with an average of 1.2 per website. On the other hand, the number of websites reported contraindications was much lower, with only $7 \%$ of the websites reported at least one contraindication, all of which were from websites sponsored by the industry. Even worse, none of the academic websites mentioned any of contraindications listed in our criteria.

While the retrospective and case series studies showed positive results in measured outcomes, it is not at the evidence level required to draw clinical conclusions for efficacy and safety. Current evidence on the efficacy of trans-axial interbody lumbosacral fusion is limited in quantity but shows symptom relief in the short term in some patients. Only $7 \%$ of the websites addressed the level of evidence of the studies that investigated 
the AxiaLIF procedure. Not surprisingly, none of them were from an industrial websites. Also, about third of the websites mentioned the phrase that the procedure is an alternative to the traditional approaches in treating patients with lower back pain.

The analysis of purported benefits and possible complications of the procedure is concerning. While all of the websites offered at least one benefit of the procedure, the majority of them were from industrial websites (mean of indication 2.4 per site). Fewer websites reported possible complications and risk of the AxiaLIF procedure. Private Websites had the poorest reporting rate with only $57 \%$ of the websites reported a possible risk of the procedure. Rectal perforation being the most serious and most common complication of the AxiaLIF mentioned only in $12 \%$ of the websites. This large imbalance between reporting the benefits and the possible complications addressed portrays the inadequacy and potential bias of the available information of AxiaLIF towards recruiting patients.

Only 8 websites offered alternative treatments to the procedure. This small number of websites addressing alternative methods of treatment is more concerning. These findings support the claims of the extensive direct-to-costumer marketing on the web which is the main effect on patients seeking information about their treatment options [15-17]. Considering the aggressive advertisement of the AxiaLIF approach, two thirds of the websites offered step-by-step description of the procedure, and one third of the websites provided illustrations and figures for the implants. Most of them were offered by the private websites with $94 \%$ of the websites offered description of the procedure and $57 \%$ offered illustrations and figures for the AxiaLIF system.

In conclusion, our findings in this study demonstrated a large inadequacy and imbalance of information made available to general public on the internet for axial lumbar interbody fusion (AxiaLIF). Not only is the information provided largely incomplete, it is potentially biased toward recruiting rather than educating the patients regarding the procedure. Unfortunately, these results are consistent with those published by multiple other groups evaluating internet information on various orthopedics conditions and procedures [13-17].

Only clear communication between the patient and physician leading to mutual understanding of the risks and benefits of treatment options increase patient confidence in their doctors and may lead to higher satisfaction with decision [30]. However, the clinical encounter is usually short, and often there is not sufficient time to discuss in-depth the complex issues that patients must understand to make a decision. Therefore, offering trusted sources of information such as informative websites, pamphlets, and other aids can increase patients' knowledge about the risks and benefits of therapeutic alternatives help them clarify their preferences [31,32]. The appropriate discussion of a patient's understanding of a procedure with a physician remains as critical as ever, and physicians should make efforts to counsel patients regarding the limitations of the information present on the internet.

\section{Study Funding}

No funding was received for or from this study.

\section{References}

1. Food and Drug Administration (2004) 510(k) Summary: TranS1 Axial Fixation System. Food and Drug Administration, Silver Spring, USA.

2. Food and Drug Administration (2008) $510(\mathrm{k})$ Summary: TranS1 AxiaLIF II System. Food and Drug Administration, Silver Spring, USA.

3. Anand N, Rosemann R, Khalsa B, Baron EM (2010) Mid-term to longterm clinical and functional outcomes of minimally invasive correction and fusion for adults with scoliosis. Neurosurg Focus 28(3): E6.

4. Aryan HE, Newman CB, Gold JJ, Acosta FL, Coover C, et al. (2008) Percutaneous axial lumbar interbody fusion (AxiaLIF) of the L5-S1 segment: initial clinical and radiographic experience. Minim Invasive Neurosurg 51(4): 225-230.

5. Cragg A, Carl A, Casteneda F, Dickman C, Guterman L, et al. (2004) New percutaneous access method for minimally invasive anterior lumbosacral surgery. J Spinal Disord Tech 17(1): 21-28.

6. Fantini GA, Pappou IP, Girardi FP, Sandhu HS, Cammisa FP, et al. (2007) Major vascular injury during anterior lumbar spinal surgery: incidence, risk factors, and management. Spine 32(24): 2751-2758.

7. Ledet EH, Tymeson MP, Salerno S, Carl AL, Cragg A (2005) Biomechanical evaluation of a novel lumbosacral axial fixation device. J Biomech Eng 127(6): 929-933.

8. MacMillan M, Fessler RG, Gillespy M, Montgomery WJ (1996) Percutaneous lumbosacral fixation and fusion: anatomic study and two-year experience with a new method. NeurosurgClin N Am 7(1): 99-106.

9. Marotta N, Cosar M, Pimenta L, Khoo LT (2006) A novel minimally invasive presacral approach and instrumentation technique for anterior L5-S1 intervertebral discectomy and fusion: technical description and case presentations. Neurosurg Focus 20(1): E9.

10. Sasso RC, Kenneth Burkus J, LeHuec JC (2003) Retrograde ejaculation after anterior lumbar interbody fusion: transperitoneal versus retroperitoneal exposure. Spine 28(10): 1023-1026.

11. Sharma AK, Kepler CK, Girardi FP, Cammisa FP, Huang RC, et al. (2011) Lateral lumbar interbody fusion: clinical and radiographic outcomes at 1 year: a preliminary report. J Spinal Disord Tech 24(4): 242-250.

12. Shen FH, Samartzis D, Khanna AJ, Anderson DG (2007) Minimally invasive techniques for lumbar interbody fusions. OrthopClin North Am 38(3): 373-386.

13. Beredjiklian PK, Bonzentka DJ, Steinberg DR, Bernstein J (2000) Evaluating the source and content of orthopaedic information on the Internet: the case of carpal tunnel syndrome. J Bone Joint Surg Am 82: 1540-1543.

14. Morr S, Shanti N, Carrer A, Kubeck J, Gerling MC (2010) Quality of information concerning cervical disc herniation on the Internet. Spine 10(4): 350-354.

15. Garcia RM, Messerschmitt PJ, Ahn NU (2009) An evaluation of information on the Internet of a new device: the lumbar artificial disc replacement. J Spinal Disord Tech 22(1): 52-57.

16. Greene DL, Appel AJ, Reinert SE, Palumbo MA (2005) Lumbar disc herniation: evaluation of information on the Internet. Spine 30(7): 826-829. 
17. Qureshi SA, Koehler SM, Lin JD, Bird J, Garcia RM, et al. (2012) An evaluation of information on the internet about a new device: the cervical artificial disc replacement. Spine 37(10): 881-883.

18. Yuan PS, Day TF, Albert TJ, Morrison WB, Pimenta L, et al. (2006) Anatomy of the percutaneous presacral space for a novel fusion technique. J Spinal Disord Tech 19(4): 237-241.

19. Nowitzke AM (2005) Assessment of the learning curve for lumbar microendoscopic discectomy. Neurosurgery 56(4): 755-762.

20. Tobler WD, Gerszten PC, Bradley WD, Raley TJ, Nasca RJ, et al. (2011) Minimally invasive axial presacral L5-S1 interbody fusion: two-year clinical and radiographic outcomes. Spine 36(20): E1296-1301.

21. Luther N, Tomasino A, Parikh K, Härtl R (2009) Neuronavigation in the minimally invasive presacral approach for lumbosacral fusion. Minim Invasive Neurosurg 52(4): 196-200.

22. Zeilstra DJ, Miller LE, Block JE (2013) Axial lumbar interbody fusion: a 6-year single-center experience. Clin Interv Aging 8: 1063-1069.

23. Issack PS, Boachie-Adjei O (2012) Axial lumbosacral interbody fusion appears safe as a method to obtain lumbosacral arthrodesis distal to long fusion constructs. HSS J 8(2):116-121.

24. Hofstetter CP, Shin B, Tsiouris AJ, Elowitz E, Härtl R (2013) Radiographic and clinical outcome after 1- and 2-level transsacral axial interbody fusion: clinical article. J Neurosurg Spine 19(4): 454-463.

25. Lindley EM, McCullough MA, Burger EL, Brown CW, Patel VV (2011) Complications of axial lumbar interbody fusion. J Neurosurg Spine 15(3): 273-279.

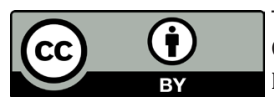

This work is licensed under Creative Commons Attribution 4.0 License

DOI: $10.19080 /$ OROAJ.2017.08.555745
26. Botolin S, Agudelo J, Dwyer A, Patel V, Burger E (2010) High rectal injury during trans-1 axial lumbar interbody fusion L5-S1 fixation: a case report. Spine 35(4): E144-148.

27. Rapp SM, Miller LE, BlockJE (2011) AxiaLIF system: minimally invasive device for presacral lumbar interbody spinal fusion. Med Devices (Auckl) 4: 125-131.

28. Mazur MD, Duhon BS, Schmidt MH, Dailey AT (2013) Rectal perforation after AxiaLIF instrumentation: case report and review of the literature. Spine J 13(11): e29-e34.

29. Siegel G, Patel N, Ramakrishnan R (2013) Rectocutaneous fistula and nonunion after TranS1 axial lumbar interbody fusion L5-S1 fixation: case report. J Neurosurg Spine 19(2): 197-200.

30. Street RL Jr, Richardson MN, Cox V, Suarez-Almazor ME (2009) Mis understanding in patient-health care provider communication about total knee replacement. Arthritis \& Rheumatism 61: 100-107.

31. O'Connor AM, Bennett CL, Stacey D, Barry MJ, Col NF, et al. (2009) Decision aids for people facing health treatment or screening decisions. Cochrane Database Syst Rev 5(10): CD001431.

32. O'Connor AM (1995) Validation of a decisional conflict scale. Medical Decision Making. 15(1): 25-30.

\section{Your next submission with Juniper Publishers will reach you the below assets}

- Quality Editorial service

- Swift Peer Review

- Reprints availability

- E-prints Service

- Manuscript Podcast for convenient understanding

- Global attainment for your research

- Manuscript accessibility in different formats

( Pdf, E-pub, Full Text, Audio)

- Unceasing customer service

Track the below URL for one-step submission https://juniperpublishers.com/online-submission.php 